\title{
The Chatty Co-Driver: A Linguistics Approach Applying Lessons Learnt from Aviation Incidents
}

Eriksson, A., Stanton, N. A.

Transportation Research Group, Faculty of Engineering and the Environment, University of Southampton, Boldrewood campus, SO16 7QF, UK

Corresponding author: Alexander Eriksson Transportation Research Group, Faculty of Engineering and the Environment, University of Southampton, Boldrewood campus, SO16 7QF, UK. Email: Alexander.eriksson@soton.ac.uk

\begin{abstract}
Drivers of contemporary vehicles are now able to relinquish control of the driving task to the vehicle, essentially allowing the driver to be completely hands and feet free. However, changes to legislation taking effect in 2016 will require the driver to be able to override the automated driving systems or switch them off completely. Initially this functionality is likely to be limited to certain areas, such as motorways. This creates a situation where the driver is expected to take control of the vehicle after being removed from the driving control-loop for extended periods of time, which places high demand on coordination between driver and automation. Resuming control after being removed from the control-loop have proven difficult in domains where automation is prevalent, such as aviation.

Therefore the authors propose the Gricean Maxims of Successful Conversation as a means to identify, and mitigate flaws in Human-Automation-Interaction. As automated driving systems have yet to penetrate the market to a sufficient level to apply the Maxims, the authors applied the Maxims to two accidents in aviation. By applying the Maxims to the case studies from a Human-AutomationInteraction perspective, the authors were able to identify lacking feedback in different components of the pilot interface. By applying this knowledge to the driving domain, the authors argue that the Maxims could be used as a means to bridge the gulf of evaluation, by allowing the automation to act like a chatty co-driver, thereby increasing system transparency and reducing the effects of being outof-the-loop.
\end{abstract}

Keywords: Automated Driving, Communication, Common Ground, Human Automation Collaboration, Transfer of Control, Learning From Incidents 


\section{Introduction}

Driving Automation (DA) involves the automation of one, or more, higher level cognitive driving tasks such as maintaining longitudinal and/or lateral vehicle position in relation to traffic and road environments (Young et al., 2007). DA distinguishes itself from vehicle automation by entailing forms of automation that involve the psychological part of driving, namely the tactical, operational and strategic levels of driving (Michon, 1985). The higher levels of control involving complex decisions and planning would qualify as DA (Young et al., 2007). By using DA in highly automated vehicles, all but the strategic level of driving could be transferred from the driver to the DA system. Only the highest level of control, i.e. goal setting on a strategical level, would remain with the driver for the main part of the journey. According to the SAE International and the Bundesanstalt für Straßenwesen (BASt), DA functionality is likely to be limited to certain geographical areas, such as motorways (Gasser et al., 2009; SAE J3016, 2016). Thus, there is a need for a human driver whose task is to resume control of the vehicle when the operational limits of DA are approached (Hollnagel \& Woods, 2005; Stanton et al., 1997). This use of DA fundamentally alters the driving task (Hollnagel \& Woods, 1983; Parasuraman et al., 2000; Woods, 1996), and will likely give rise to automation surprises (Sarter et al., 1997) and ironies (Bainbridge, 1983) such as unevenly distributed workload (Hollnagel \& Woods, 1983, 2005; Kaber \& Endsley, 1997; Kaber et al., 2001; Norman, 1990; Parasuraman, 2000; Sheridan, 1995; Woods, 1993; Young \& Stanton, 1997, 2002, 2007b), loss of Situation Awareness (SA) and poor vigilance (Endsley, 1996; Endsley et al., 1997; Kaber \& Endsley, 1997; Kaber \& Endsley, 2004; Kaber et al., 2001; Sheridan, 1995; Woods, 1993), with the risk of ending up Out-Of-the-Loop (Endsley, 1996; Endsley et al., 1997; Kaber \& Endsley, 1997; Kaber \& Endsley, 2004; Kaber et al., 2001; Norman, 1990) as well as the possibility of mode errors (Andre \& Degani, 1997; Degani et al., 1995; Leveson, 2004; Norman, 1983; Rushby et al., 1999; Sarter \& Woods, 1995; Sheridan, 1995)

These problems manifest when the driver is required to return to the driving control loop, either due to mechanical malfunctions, sensor failure, or when the vehicle approaches a context where automation is no longer supported, such as adverse weather conditions, adverse behaviour of other road users or unforeseen events in the road environment. An example of a contextual restriction in contemporary DA is Automated Cruise Control (ACC). Using ACC for prolonged periods of time may cause drivers to forget that ACC system is still engaged when it is time to leave the motorway, which, in busy 
traffic where vehicle speed is limited by other road users, could result in an increase of vehicle velocity when taking an off ramp as there are no vehicles in front of the car (Norman, 2009). It is therefore important to ensure that the driver receives the support and guidance necessary to safely get back in to the vehicle control loop (Cranor, 2008).

Failure-induced transfer of control has been extensively studied (see Desmond et al., 1998; Molloy \& Parasuraman, 1996; Stanton et al., 1997; Strand et al., 2014; Young \& Stanton, 2007a). It takes approximately $<1$ second for a driver to respond to a sudden braking event in traffic (Summala, 2000; Swaroop \& Rajagopal, 2001; Wolterink et al., 2011). A technical failure leading to an unplanned and immediate transfer of vehicle control back to the driver will likely give rise to an incident as the $0.3 \mathrm{~s}$ time headway (the time between the leading and host vehicle as a function of velocity and distance) is shorter than driver response times (Willemsen et al., 2015). Given that drivers are unlikely to be able to intervene in situations where a response time of less than one second is required, it is arguable that the likelihood of failure-induced transfer of control must be made negligible. The feasibility of DA rests on the systems' ability to cope with all but the most severe technical failures without loss of control on public roads.

Routine transfers of control under 'normal' circumstances has not been studied as extensively as failure-induced transfers of control (Eriksson \& Stanton, 2017), therefore many factors still need to be explored, such as: what method and time is used to transfer control, how will the Human Machine Interface (HMI) convey necessary information, and how will the transfer of control be managed by the driver (Beiker, 2012; Hoc et al., 2009; Merat et al., 2014). Christoffersen and Woods (2002) stated that in order to ensure coordination between human and machine, the system state must be transparent enough for the agents to understand problems and activities, as well as the plans of other agents and how they cope with external events such as traffic and sensor disturbances (Beller et al., 2013; Inagaki, 2003; Kaber et al., 2001; Klein et al., 2004; Rankin et al., 2013; Weick et al., 2005). This decreases the size of what Norman (2013) refers to as the gulf of evaluation, which is the effort required to interpret the state of the system and determine how well the behaviour corresponds to expectations. This puts a requirement on designers and engineers of automation to make the operational limits transparent (Seppelt \& Lee, 2007).

A crucial part of ensuring system transparency is to ensure that Common Ground (CG) has been established. Common Ground is defined as the sum of two or more peoples (or agents) mutual beliefs, knowledge and suppositions (Clark, 1996; Heath et al., 2002; Hoc, 2001; Huber \& Lewis, 2010; Keysar et al., 1998; Stalnaker, 2002; Vanderhaegen et al., 2006). CG may be achieved by ensuring that the driver receives feedback that either; acknowledges that inputs have been registered, or that an 
error in the input transmission has occurred. According to Brennan (1998), feedback of this type is of utmost importance in achieving CG. Ensuring that CG is achieved is crucial in a highly automated vehicle as the driving task is distributed between driver and automation and to succeed both entities need to be aware of the other entities actions (Hollan et al., 2000; Hutchins, 1995a, 1995b; Wilson et al., 2007). An example of how this is applied in human-human communication is the use of acknowledging phrases such as "roger" when acknowledging statements in nuclear power plant control rooms and on the flight deck (Min et al., 2004).

Furthermore, if the system provides continuous, timely, and task relevant feedback to the driver during for example highly automated driving, it is possible to reduce the cognitive effort of understanding the system state and whether user inputs are registered or not when it is time to resume manual control (Brennan, 1998; Clark \& Wilkes-Gibbs, 1986; Sperber \& Wilson, 1986). According to Patterson and Woods (2001) the purpose of the handover is to make sure that the incoming entity does not have an incorrect model of the process state, is aware of significant changes to the process, is prepared to deal with effects from previous events, is able to anticipate future events, and have the necessary knowledge to perform their duties. This is supported by research from Beller et al. (2013) who found that drivers who received automation reliability feedback were on average 1.1 seconds faster to respond to a failure, which, according to Summala (2000), is approximately the time it takes to respond to an unexpected braking event during manual driving.

Evidently, appropriate feedback may reduce the time needed for a successful takeover as it could allow the driver to anticipate the need to intervene. Research by Kircher et al. (2014) has shown that drivers adapt their usage of automation by disengaging DA systems before operational limits are reached. These insights indicate that drivers are able to anticipate when to disengage automation in contemporary systems to ensure safe transfers of control. This does not necessarily mean that drivers will be able to adapt in such a way using systems in the future, as the majority of the driving task will be automated and the driver will be less involved in the driving task.

\subsection{Principles of communication}

In order to demonstrate the importance of communication and feedback Norman (1990) posited a thought experiment. In the first part of the experiment an airline pilot handed over control to the aircraft autopilot. In the second part of the experiment control was handed to a co-pilot instead of the autopilot. Norman argued that the task is "automated" from the captains point of view in both examples. If an event were to occur mid-flight to create an imbalance in the aircraft, both autopilot and co-pilot have the ability to successfully compensate for the imbalance. However, there is a large difference in the way the information about compensatory actions would be communicated to the captain. In the case of the autopilot, the compensatory behaviour would only be communicated 
through the changes of controller settings in the cockpit and could easily be missed by the crew, as they are out-of-the-loop. In the case of the co-pilot, compensatory actions would be executed by means of the physical movements of the co-pilot that is required to change controller settings and to move control yokes as well as verbal communication such as "the aircraft started to bank to the left so I have had to increase the right wing down setting of the control wheel". Thus, in the case of the copilot, the compensatory actions taken would be significantly more obvious to the captain. Examples of such situations are given in Section 2 of this paper.

In a DA context, a similar, but strictly theoretical scenario could be that the DA system compensates for an imbalance in the steering system caused, for example, by a partially deflated tire, by countersteering. If the vehicle utilised steer-by-wire technology, with which the physical connection between the wheels and the steering wheel is replaced by sensors, torque motors, and servos, it would be possible for the DA system to compensate for this imbalance by adjusting the position of the wheels to produce a countersteering effect without moving the steering wheel. If this was the case, and the driver was prompted to resume control it is very unlikely that the transient manoeuvre would be carried out in a safe manner as the vehicle would suddenly turn as the countersteering ceased at the moment of control transfer. If the DA system was to mimic the countersteering effect on the wheels on the steering wheel, thus quite clearly communicating that compensatory action is being taken the transfer of control may be successful. The driver is then able to continue applying counterforce by maintaining the same steering wheel angle as the DA system when the compensatory action was carried out. Contemporary research has found similar results whereby the steering torque has changed from when drivers relinquish control to when they resume control from the automation, such a change in torque is experienced when vehicle velocity changes during transit (Russell et al., 2016).

Norman concluded that when automated systems work in silence, not communicating its actions and state, with the crew being out-of-the-loop, a sudden automation failure or shutdown due to reaching the operational limits of the systems, might take the crew by surprise leading to an unrecoverable situation. Furthermore, he stated that feedback is essential in updating operators mental models of the system (thus achieving Common Ground) and that feedback is essential for the appropriate monitoring and error detection and correction (Norman, 1990). In an effort to reduce the gulf of evaluation (Norman, 2013) and to increase behavioural transparency of automation to a similar level to that of a human co-pilot, the authors would like to introduce a "Chatty Co-Driver paradigm" (Eriksson \& Stanton, 2016; Hoc et al., 2009; Stanton, 2015). The authors argue that human automation interaction may be facilitated through the application of the cooperative principle (Grice, 1975) as a heuristic in designing the automation human-machine interface and feedback. To ensure that system feedback is communicated in an effective manner it has to adhere to certain principles. As part of the cooperative principle, Grice (1975) posited four maxims for successful conversation: Quantity, Quality, Relation and Manner detailed below. 
1. The Maxim of Quantity states that contributions should be made as informative as required without contributing more information than required to do so.

2. The Maxim of Quality states that information provided should not be false, and it should be supported by adequate evidence.

3. The Maxim of Relation states that the information contributed should be relevant for the task/activity, context and the need in the current situation.

4. The Maxim of Manner relates to how the information is provided rather than what information is provided. The maxim states that obscurity and ambiguity should be avoided, information should be conveyed briefly and orderly.

The Gricean maxims have primarily been used to assess human-human interaction (Attardo, 1993; Rundquist, 1992; Surian, 1996) and one study used the Gricean maxims to design automated system etiquette in aviation resulting in an increase in operator performance when automation etiquette was optimal and vice versa (Sheridan \& Parasuraman, 2005).

However, the potential use of the Gricean maxims in assessing information quality and its effects on coordination in human machine/automation interaction has yet to be explored. In DA the crucial part of the coordinative act is the transfer of vehicle control between man and machine. A successful control transition necessitates a meaningful exchange of information between driver and automation. Through applying the chatty co-driver paradigm, feedback could be designed in a similar fashion to the feedback provided by a human co-pilot in aviation, for example by verbally announcing decisions and actions, and changes to controller inputs are salient through physical movements of controllers by the human pilot. Through the application of the Gricean maxims in this way, it could be possible to determine when and how to display information in a contextually and temporally relevant way.

\section{Case Studies}

Contemporary Driving Automation is still in its infancy and therefore currently restricted to test tracks, pre-determined test-beds and manufacturer prototypes. Therefore, the perspectives from Section 1 will be applied to the aviation domain in which autopilots are commonplace and where human-automation interaction is prevalent.

\subsection{Method}

To illustrate the explanatory ability of the maxims they will be applied to two case studies, the Air France 447 crash (Bureau d'Enquêtes et d'Analyses pour la sécurité de l'aviation civile, 2012, BEA), and the ComAir Flight 3272 crash (National Transportation Safety Board, 1997, NTSB), because aviation is a domain where communication breakdowns are regarded as a serious threat to safety (Molesworth \& Estival, 2015). The analysis of the case studies is based on data from the official 
investigations by BEA (2012) and NTSB (1997) as well as previous analysis by Eriksson and Stanton (2015).

\subsection{Air France 447}

\subsubsection{Synopsis}

On May 312009 an Airbus A330-200 operated by Air France was scheduled to carry 216 passengers and twelve crew members on flight AF447 between Rio de Janeiro Galeão and Paris Charles de Gaulle. The captain was assigned Pilot Not Flying (PNF) and one of the co-pilots was assigned Pilot Flying (PF). AF447 was in cruise at Flight Level 350 (FL350) in calm conditions at the start of the Cockpit Voice Recorder (CVR) recording, just after midnight. At 01:52 the captain woke the resting co-pilot and requested that he were to take his place as the PNF, 8 minutes later the PF briefed the newly arrived co-pilot. In the briefing the PNF mentioned that the recommended maximum altitude (REC MAX) was limiting their ability to climb above a turbulent area due to a higher than expected temperature. Following the briefing, the captain left the PF and the replacement PNF to continue the flight. At 02:08 the PNF suggested a heading alteration of 12 degrees to avoid a turbulent area, the crew also decided to decrease speed from Mach 0.82 to Mach $0.8(\sim 529 \mathrm{kt})$ and to turn on engine deicing. At 02:10:05 the autopilot and the auto-thrust disconnected, likely due to all of the pitot probes of the Airbus freezing over, resulting in unreliable speed readings. Following the autopilot disconnection the PF said "I have the controls" indicating he was in control of the aircraft.

The PF simultaneously gave a nose up and left input as a response to the aircraft rolling to the right at the time of autopilot disconnecting. The actions of the PF triggered a stall warning as angle of attack increased beyond the flight envelope boundaries at Mach 0.8 (Fig 1. Angle of Attack, AOA > $4^{\circ}$ ). This was the start of a series of events of miscommunication between the flight crew and between the crew and aircraft. During the remaining 4 minutes and 23.8 seconds the aircraft continued to climb, leaving the lift envelope, trading kinetic energy for potential energy, until it unavoidably started to descend. The PF, unaware of the situation, continued to apply nose up inputs which further increased the AOA which, from 02:12 to the end of the flight were on average around $40^{\circ}$. The last recorded vertical speed value was $-10,912 \mathrm{ft} / \mathrm{min}$ as it crashed into the Atlantic Ocean.

\subsubsection{Analysis}

At 02:10:04 a Cavalry charge sounded in the cockpit of AF447, indicating that the autopilot had disengaged. An immediate change in roll angle from $0^{\circ}-8.4^{\circ}$ without any sidestick input followed the autopilot disengagement. The PF responded appropriately by acknowledging the event by stating he had the controls, thereby making the PNF aware that manual control was resumed. At this point the PF's task was to maintain control of the aircraft and the PNF's task was to identify the fault and 
ensure that the designated flight path was followed. The PNF does this by checking the instruments and the Electronic Centralised Aircraft Monitor (ECAM) display.

The ECAM is designed to provide pilots with information in a quick and effective manner as well as displaying the necessary corrective actions needed to resolve any errors. As the PNF tried to identify the reason for the unexpected disconnection of the autopilot by checking the ECAM messages (see Figure 1a) there was nothing to indicate that the autopilot disconnect had anything to do with the pitot probes freezing over, causing inaccurate speed readings. The only ECAM indication of a speed-related error was a message that indicated that the max speed was Mach 0.82, which, according to the BEA investigation, could be misinterpreted as the aircraft being in an over-speeding situation.
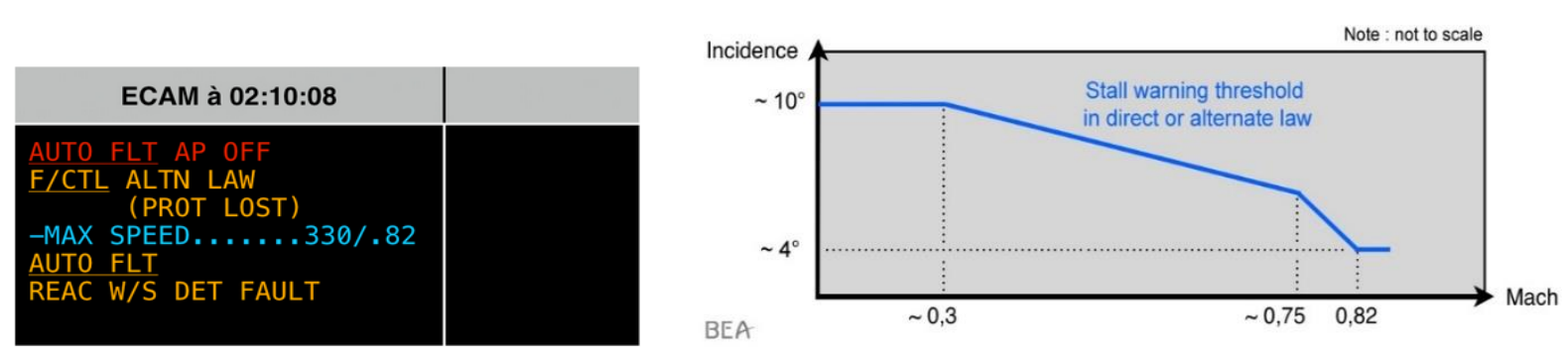

Fig. 1. A) Information readily available for PNF at the time of autopilot disconnect. B) AOA threshold for stall warning at different speeds. Source: BEA www.bea.aero

At the time of the transition of control of the aircraft from autopilot to pilot there was nothing to indicate why the transfer had occurred, and what future actions needed to be taken to ensure continued safe operation of the flight.

According to Patterson and Woods (2001), the main purpose of a transfer of control or handover is to ensure that the agent taking over control has a correct mental model of the current process state and is aware of any changes to the process. The agent resuming control must also be prepared to deal with the effects from previous events and needs to be able to anticipate future events. These requirements failed to be fulfilled at the time of the transfer of control, as neither the PF, nor the PNF, succeeded in identifying the underlying cause of the autopilot disengagement in the initial period after control was transferred. As the PF and PNF failed to create an accurate mental model of the current system state due to lacking system feedback, their action responses to the events unfolding were inappropriate for the situation, and thus resulted in worsening, rather than improving the situation.

Using a Gricean perspective it is possible to identify several violations of the Gricean maxims in the moments where control was transferred from autopilot to PF. The absence of any information related to the pitot readings being inaccurate is a clear violation of the Maxim of Quantity as information clearly was not sufficient to provide the PF/PNF with the necessary information to assess the situation. The Maxim of Quality was also violated as the MAX SPEED information was of no help in resolving the 
situation as at the time of the incident, the aircraft was nowhere near an over-speeding situation, thus information indicating an over-speeding risk was provided of which no underlying evidence of such a risk was present. Furthermore, the Maxim of Relation was violated as the MAX SPEED information was irrelevant to the context at hand and did not assist in creating an accurate mental model. The Maxim of Manner was also violated as the ambiguous nature of the speed warning, giving an indication of the risk of over-speeding rather than the erroneous readings of the pitot probes.

\subsection{Com Air 3272}

\subsubsection{Synopsis}

Comair flight 3272, an Embraer EMB 120 Brasilia, departed Covington, Kentucky on its way to the Detroit Metropolitan/Wayne Country Airport, on January $9^{\text {th }} 1997$ about 15:08, with 2 flight-crew members, 1 flight attendant, and 26 passengers on board. The flight was routine with some intermittent, light chop. At 15:52.13 the ATC cleared the pilots to descend to 4,000 ft mean sea level (msl). The pilots acknowledged and complied with the clearance. At 15:54.05 the pilot initiated a left turn to heading $090^{\circ}$ by changing the heading setting for the autopilot. According to Flight Data Recorder (FDR) data at 15:54.08 the aircraft was in a shallow left bank remaining at 4000ft msl. As the aircraft reached its assigned altitude of $4000 \mathrm{ft}$ msl the autopilot switched mode from "Altitude Pre Select (arm)" to "Altitude Hold". At 15:54.10, the aircraft was flying at an airspeed of 156kt and the roll attitude of the aircraft had steepened to an approximate $23^{\circ}$ left wing down bank, causing the autopilot to turn the control wheel position (CWP, the control wheel that control aircraft roll angle) in a right wing down direction. Unfortunately, this corrective action had no effect as the left wing down angle continued to steepen.

At 15:54.15 the left bank continued to steepen whilst the autopilot continued to apply compensatory measures by turning the CWP to apply right wing down commands. Approximately 15 seconds later the bank angle was steepening beyond $45^{\circ}$ at which point the autopilot disconnected and the stick shaker-engaged. In less than two seconds after the disconnection of the autopilot the CWP moved from $18^{\circ}$ right wing down command to $19^{\circ}$ left wing down command, the roll increased from $45^{\circ}$ left to $140^{\circ}$ and pitch attitude decreased from $2^{\circ}$ nose up to $17^{\circ}$ nose down. At 15:54.25 the sound of the stick-shaker ceased, followed by an utterance of "Oh" from both the Captain and the First Officer. Approximately 30 seconds after the autopilot disengagement the aircrafts left roll attitude increased beyond $140^{\circ}$ and the pitch attitude approached $50^{\circ}$ nose down. According to the CVR data the ground proximity warning system triggered the "bank angle" aural warning follow by three chimes and the autopilot aural warning repeatedly until the end of the recording.

\subsubsection{Analysis}


As Comair 3272 descended to $4000 \mathrm{ft}$ msl the pilots were instructed to carry out a heading change to $090^{\circ}$ by entering the new heading into the autopilot. The autopilot responded by banking to the left to achieve the desired heading by adjusting the ailerons and thus, the CWP in the cockpit. During the descent the aircraft had accumulated ice on the aerofoil and as the aircraft entered the left bank. NTSB theorise that the change in bank angle caused asymmetrical ice self-shedding which combined with aileron deflection effects caused the left bank angle to steepen. As the bank angle steepened beyond the instructed bank angle the autopilot's design logic responded by instructing the aileron servos to move the ailerons, and the CWP, in a RWD fashion to counter the increasing roll rate. When the autopilot was working in the heading mode the maximum commanded bank angle was $25^{\circ}$, which was exceeded as the bank angle increased, this limitation reduced the compensatory behaviour that the autopilot could carry out. When the maximum autopilot bank angle of $25^{\circ}$ is exceeded, no alarm nor any other cues are issued in the cockpit, the first indication occurs when the bank angle exceeds $45^{\circ}$ and the autopilot automatically disengage. As the bank angle steepened beyond $45^{\circ}$, the autopilot disengaged and the following events occurred simultaneously: the stick shaker activated. A repeated “ding, ding, ding, autopilot" aural alert sounded, red autopilot fail/disengage lights illuminated on the autopilot, flight control, and master warning panels, the aircraft went from $45^{\circ}$ left bank to $140^{\circ}$ left bank, the CWP changed from $18^{\circ}$ RWD to $19^{\circ} \mathrm{LWD}$ and the pitch attitude changed from $2^{\circ}$ nose up to $19^{\circ}$ nose down.

This particular accident is similar to the one described in Section 1. The official investigation suggested that if one of the pilots had been gripping the control wheel to monitor automation performance the error would likely have been detected. However, as humans are notoriously bad at maintaining sustained attention for longer periods time of it is arguable that such behaviours are unlikely and should not be expected (Heikoop et al., 2016; Molloy \& Parasuraman, 1996). From a Gricean perspective, the control wheel was designed in such a fashion that any changes in CWP were not salient enough. The control wheel design does provide information that is both correct, relevant to the task, and the design carries enough information to understand what is going on, thus fulfilling the requirements of the Maxim of Quantity, Maxim of Quality and Maxim of Relation. However, the control wheel does not provide unambiguous and salient information, thereby violating the Maxim of Manner.

The autopilot feedback was also found insufficient. As the aircraft passed the $25^{\circ}$ command limit of the autopilot no alarm sounded and no feedback was shown in the cockpit displays. No feedback was issued at all until the bank angle exceeded $45^{\circ}$ and the autopilot disconnected along with the autopilot warning. As there was no indication of the aircraft approaching and exceeding the autopilots performance boundaries the pilots were unaware of the severity of the aerodynamic degradation. Thus, the compensatory actions taken by the aircraft until the autopilot reached its bank-limit and 
disengaged. From a Gricean perspective, the lack of warning violates the Maxim of Quantity, as there is no information presented to the pilots regarding the bank angle exceeding $25^{\circ}$. Furthermore the lack of information implies that the systems was working normally, thus violating the Maxim of Quality, and the Maxim of Relation, as the system was past its interaction boundary (the bank angle envelope of $25^{\circ}$ in which the autopilot could apply RWD/LWD commands) and had feedback been presented, the pilots would have had a chance to compensate manually. Due to the lack of any feedback, The Maxim of Manner was violated in the sense that there is no information/feedback that could be assessed using the maxim.

The FDR data indicated that the pilots responded by applying RWD commands on the control wheel within one second after the autopilot disconnected to counter the sudden increase in left bank. If changes to the CWP had been more salient, clearly indicating both the corrective actions taken by the autopilot in terms of bank angle but also the force that was applied to the control wheel the pilots would have had a clear indication of the actions taken by the autopilot. Furthermore, had there been a warning or a notice on one of the cockpit displays when the autopilot exceeded its interaction boundary the might have been made aware of the autopilot struggling to maintain the bank angle required for the heading change due degrading aerodynamic characteristics of the aerofoil. Such an indication would have been in accordance with the Maxim of Relation, through providing temporally and contextually relevant information. This would have allowed the pilots to resume manual control earlier and have allowed them to increase airspeed and abort the heading change, thus reducing the bank angle, before the autopilot reached its $45^{\circ}$ performance boundary and disconnected.

\subsection{Summary of Case studies}

To summarise the results of the case studies from a Gricean perspective it is clear that there was several Maxim violations that contributed to the crash of Air France AF447 and Comair 3272. The maxims highlighted issues relating to lack of, or non-salient, feedback to mode changes and system actions. Furthermore, the use of the maxims allowed for the identification of an issue related to nonsalient feedback of a piece of equipment that otherwise functioned according to specification, namely the autopilot controlled changes to CWP as shown in Table 1.

Table 1: A summary of the maxim violations in each part of the case studies. Key: $\checkmark=$ maxim fulfilled, $\mathbf{x}=$ maxim violated
AF447
Comair
Comair

speed readings

control wheel

Autopilot warning

\begin{tabular}{llll}
\hline Maxim of Quantity & $\boldsymbol{x}$ & $\checkmark$ & x \\
Maxim of Quality & $\boldsymbol{x}$ & $\checkmark$ & $x$
\end{tabular}


The Maxims show promise in identifying flawed communication in the human-cockpit system, therefore they have potential as a tool to inform the design of similar systems. Such a system could be highly automated driving systems in which interaction could be designed in such a way that events similar to the case studies above may be avoided in future automated vehicles.

\section{Lessons Learnt}

The case studies in Section 2 have illustrated how operator mental models deteriorate as they are removed from the control loop. In the case studies this resulted in loss of life due to crashes when the operator suddenly had to resume control with an inaccurate mental model after prolonged exposure to automated systems with no, or poor feedback. The motor industry have been spared of such issues, but with the introduction of new technology, drivers have been able to relinquish control of certain sub-tasks of the driving task. These systems have allowed drivers to take their feet of the pedals, and more recently, have their lane position controlled automatically as well. Although drivers have yet to be able to fully relinquish control to the vehicle, recent amendments to the Vienna Convention on Road Traffic now enables drivers to be fully hands and feet free as long as the system "can be overridden or switched off by the driver" (Miles, 2014).

This amendment, when it takes effect in March 2016, will allow autonomous vehicles owned by the public to be driven hands and feet free, on public roads. The change in legislation implies significant changes to the driving task. Whilst contemporary DA systems require intermittent driver feedback, by for example, touching the steering wheel or the indicator stalk thus maintaining some level of driver engagement, the amended section of the Vienna Convention of Road Traffic will allow the driver to be completely out-of-the-loop.

As drivers are given more freedom to relinquish the driving task to the automated systems their role in the DA system is altered, approaching that of a pilot flying by means of the autopilot (Hollnagel \& Woods, 1983; Parasuraman et al., 2000; Woods, 1996). The driver will, much like a pilot, have to monitor the DA system for errors or deviant behaviours and will be expected to resume control when something goes wrong or when operational limits are reached (Hollnagel \& Woods, 2005; SAE J3016, 2016; Stanton et al., 1997).

As shown in section 2, pilots may fail to successfully recover their aircraft when the automated systems failed to cope despite being subjected to extensive training before receiving their pilotslicense as well as regular training sessions of fringe scenarios in simulators. This training is supposed to prepare pilots for rare occurrences such as: degraded aerodynamic properties of the aerofoil due to 
icing, autopilot operational limits, or the safety envelope of an Airbus A380 in different laws, which allows them to adapt to ever-changing conditions. The fact that highly trained, professional pilots sometimes struggle to cope in such high-complexity situations are particularly worrying as drivers soon will be able to purchase vehicles equipped with DA that enables similar features in the vehicle which will allow hands and feet free driving without any additional training.

Section 2 showed that breakdowns in human-machine communication could be attributed to the cause of the accidents. In the aviation domain, communication breakdowns are considered a serious threat to safety (Molesworth \& Estival, 2015), and the same should be considered for the driving domain. Especially since there is a differing degree of complexity in the DA domain caused by a large fleet of vehicles occupying a relatively small space where non-connected road users such as pedestrians, cyclists as well as wild animals co-exist. This puts even higher demands on Engineers responsible for designing the driver interface for the DA systems.

The case studies in Section 2 clearly identify, by means of the Gricean Maxims, non-salient feedback, non-existing feedback, and erroneous feedback to be a contributing factor in the accidents that transpired. Humans are known to be poor monitors in situations where passive monitoring is required (Heikoop et al., 2016; Molloy \& Parasuraman, 1996), and as they are removed from the driving loop, measures must be taken to ensure that DA systems does not succumb to similar issues as described in the case studies. Aviation accidents may be rare, but the consequences of similar communication issues being present in DA systems, coupled with the exposure of untrained operators to such systems, has the potential to be dire.

To ensure that incidents caused by poor communication between man and machine is reduced Human Factors Engineers must aim to reduce the gulf of evaluation, thereby retaining driver common ground and thus a representative mental model of the DA system (Klein et al., 2004; Norman, 1990). This could potentially be done using a "Chatty Co-Driver paradigm" (Eriksson \& Stanton, 2016; Hoc et al., 2009; Stanton, 2015). The Chatty Co-Driver paradigm tries to reduce the gulf of evaluation by providing feedback in a similar manner to what a co-pilot would do, why, and what its next action is (Wiener, 1989) thus increasing system transparency (Christoffersen \& Woods, 2002).

Such feedback could entail information regarding what the vehicle sensors are able to register, thus providing an indication of the limitations of the vehicle radars as well as whether the vehicle have picked up objects entering the automated vehicles trajectory (Jenkins et al., 2007; Stanton et al., 2011).

Furthermore, as shown by Beller et al. (2013), contextually relevant information could reduce the time to transfer of control as it brings the driver back into the control loop by restoring driver mental models and thus reduces the likelihood of an escalation of cognitive activities (Woods \& Patterson, 2000). Furthermore, research by Eriksson et al. (2015) indicate that information needs change 
depending on contextual and temporal factors. Based on the aforementioned maxims of successful conversation (Grice, 1975) , the authors propose that by adhering to the Maxim of Quantity, Quality, Relation, and Manner in designing automated system the gulf of evaluation could be reduced, and system transparency could be increased.

\section{Concluding remarks}

This paper highlighted some of the problems drivers will face when encountering DA systems, such as automation surprises, and ending up out of the loop. When drivers are out of the loop and a change in operational conditions occur, requiring a control transition from DA to manual control, the driver must have access to sufficient information to safely complete the transition. Due to the lack of DA systems available to the public, two case studies were presented from the aviation domain. It was demonstrated that highly trained professionals failed to safely resume control after a control transition due to poor, or lacking feedback, from the automated system.

By applying the Gricean maxims of successful conversation to the case studies from a humanautomation interaction perspective, the authors were able to identify lacking feedback in different components of the pilot interface. In addition, it is argued that the maxims could be used as a means to bridge the gulf of evaluation in contemporary DA systems, by allowing the DA system to act like a chatty co-driver, thereby increasing system transparency and reducing the effects of being out of the loop. Some high level proposals for design based on the maxims are provided in Table 2 below.

Table 2: Design proposals for information presentation based on the Gricean Maxims.

\section{Design proposal}

$\begin{array}{ll}\text { Maxim of Quantity } & \text { Avoid oversaturating the information presentation modality by } \\ \text { Maxim of Quality } & \text { limiting the information presented to the bare necessity. } \\ \text { - } & \text { Ensure that the information presented is based on reliable data } \\ \text { Maxim of Relation } & \text { If the information is based on unreliable data, ensure that it is } \\ \text { Ensure that the presented information is contextually relevant, for } \\ \text { example based on Michon's (1985) operational, tactical and } \\ \text { strategical levels of information. } \\ \text { Do not present information that is non-relevant to accomplish the } \\ \text { task. } \\ \text { Avoid ambiguity by for example reducing similarities of auditory } \\ \text { tones or, increasing contrast between similar modes in the visual } \\ \text { HMI. }\end{array}$


- Ensure that the right information is presented in the right modality, for example, urgent signals could be presented both haptically, auditory and visually whereas non-urgent information could be presented visually in the HMI (Meng \& Spence, 2015).

\section{Acknowledgements}

The research presented in this paper was conducted within the scope of the project HFAuto - Human Factors of Automated Driving (PITN-GA-2013-605817). 


\section{References}

Andre, A., \& Degani, A. (1997). Do you know what mode you're in? An analysis of mode error in everyday things. Human-Automation Interaction: Research and Practice, pp 19-28.

Attardo, S. (1993). Violation of conversational maxims and cooperation: The case of jokes. Journal of Pragmatics, vol 19, no 6, pp 537-558.

Bainbridge, L. (1983). Ironies of Automation. Automatica, vol 19, no 6, pp 775-779.

Beiker, S. A. (2012). Legal aspects of autonomous driving: The need for a legal infrastructure that permits autonomous driving in public to maximize safety and consumer benefit. Santa Clara Law Review.

Beller, J., Heesen, M., \& Vollrath, M. (2013). Improving the Driver-Automation Interaction: An Approach Using Automation Uncertainty. Human Factors: The Journal of the Human Factors and Ergonomics Society, vol 55, no 6, pp 1130-1141.

Brennan. (1998). The Grounding Problem in Conversations With and Through Computers. In S. R. F. R. J. Kreuz (Ed.), Social and cognitive psychological approaches to interpersonal communication (pp. 201-225). Hillsdale, NJ: Lawrence Erlbaum.

Bureau d'Enquêtes et d'Analyses pour la sécurité de l'aviation civile. (2012). Final Report: On the accident on 1st June 2009 to the Airbus A330-203 registered F-GZCP operated by Air France flight AF 447 Rio de Janeiro - Paris.

Christoffersen, K., \& Woods, D. D. (2002). How to Make Automated Systems Team Players. Advances in Human Performance and Cognitive Engineering Research, vol 2, pp 1-12.

Clark, H. H. (1996). Using Language: Cambridge University Press.

Clark, H. H., \& Wilkes-Gibbs, D. (1986). Referring as a Collaborative Process. Cognition, vol 22, no 1 , pp 1-39.

Cranor, L. F. (2008). A framework for reasoning about the human in the loop. Paper presented at the Proceedings of the 1st Conference on Usability, Psychology, and Security.

Degani, A., Shafto, M., \& Kirlik, A. (1995). MODE USAGE IN AUTOMATED COCKPITS: SOME INITIAL OBSERVATIONS. Paper presented at the International Federation of Automatic Control.

Desmond, P. A., Hancock, P. A., \& Monette, J. L. (1998). Fatigue and automation-induced impairments in simulated driving performance. Human Performance, User Information, and Highway Design, no 1628, pp 8-14.

Endsley, M. R. (1996). Automation and Situation Awareness. In R. Parasuraman \& M. Mouloua (Eds.), Automation and human performance: Theory and applications.

Endsley, M. R., Onal, E., \& Kaber, D. B. (1997). The impact of intermediate levels of automation on situation awareness and performance in dynamic control systems. Global Perspectives of Human Factors in Power Generation, pp 77-712.

Eriksson, A., Marcos, I. S., Kircher, K., Västfjäll, D., \& Stanton, N. A. (2015). The Development of a Method to Assess the Effects of Traffic Situation and Time Pressure on Driver Information Preferences Engineering Psychology and Cognitive Ergonomics (pp. 3-12): Springer International Publishing.

Eriksson, A., \& Stanton, N. A. (2015). When communication breaks down or what was that? - The importance of communication for successful coordination in complex systems. Paper presented at the 6th International Conference on Applied Human Factors and Ergonomics, Las Vegas, NV.

Eriksson, A., \& Stanton, N. A. (2016). The Chatty Co-Driver: A Linguistics Approach to HumanAutomation-Interaction. Paper presented at the IEHF2016.

Eriksson, A., \& Stanton, N. A. (2017). Take-over time in highly automated vehicles: non-critical transitions to and from manual control. Human Factors.

Gasser, T. M., Arzt, C., Ayoubi, M., Bartels, A., Bürkle, L., Eier, J., et al. (2009). Legal consequences of an increase in vehicle automation. 
Grice, H. P. (1975). Logic and Conversation. In P. Cole \& J. L. Morgan (Eds.), Speech Acts (pp. 41-58). New York: Academic Press.

Heath, C., Svensson, M. S., Hindmarsh, J., Luff, P., \& vom Lehn, D. (2002). Configuring Awareness. Computer Supported Cooperative Work (CSCW), vol 11, no 3-4, pp 317-347.

Heikoop, D. D., de Winter, J. C. F., van Arem, B., \& Stanton, N. A. (2016). Psychological constructs in driving automation: a consensus model and critical comment on construct proliferation. Theoretical Issues in Ergonomics Science, vol 17, no 3, pp 284-303.

Hoc, J.-M. (2001). Towards a cognitive approach to human-machine cooperation in dynamic situations. International Journal of Human-Computer Studies, vol 54, no 4, pp 509-540.

Hoc, J.-M., Young, M. S., \& Blosseville, J.-M. (2009). Cooperation between drivers and automation: implications for safety. Theoretical Issues in Ergonomics Science, vol 10, no 2, pp 135-160.

Hollan, J., Hutchins, E., \& Kirch, D. (2000). Distributed Cognition: A New Foundation for HumanComputer Interaction Research. ACM Transactions on Human-Computer Interaction: Special Issue on Human-Computer Interaction in the New Millennium, vol 7, no 2, pp 174-196.

Hollnagel, E., \& Woods, D. D. (1983). Cognitive Systems-Engineering - New Wine in New Bottles. International Journal of Man-Machine Studies, vol 18, no 6, pp 583-600.

Hollnagel, E., \& Woods, D. D. (2005). Joint Cognitive Systems Foundations of Cognitive Systems Engineering: CRC Press.

Huber, G. P., \& Lewis, K. (2010). Cross-Understanding: Implications for Group Cognition and Performance. Academy of Management Review, vol 35, no 1, pp 6-26.

Hutchins, E. (1995a). Cognition in the Wild: MIT Press; Cambridge Mass.

Hutchins, E. (1995b). How a Cockpit Remembers Its Speed. Cognitive Science, vol 19.

Inagaki, T. (2003). Adaptive Automation: Sharing and Trading of Control. In E. Hollnagel (Ed.), Handbook of Cognitive Task Design (pp. 147-169).

Jenkins, D. P., Stanton, N. A., Walker, G. H., \& Young, M. S. (2007). A new approach to designing lateral collision warning systems. International Journal of Vehicle Design, vol 45, no 3, pp 379-396.

Kaber, D. B., \& Endsley, M. R. (1997). Out-of-the-loop performance problems and the use of intermediate levels of automation for improved control system functioning and safety. Process Safety Progress, vol 16, no 3, pp 126-131.

Kaber, D. B., \& Endsley, M. R. (2004). The effects of level of automation and adaptive automation on human performance, situation awareness and workload in a dynamic control task. Theoretical Issues in Ergonomics Science, vol 5, no 2, pp 113-153.

Kaber, D. B., Riley, J. M., Tan, K.-W., \& Endsley, M. R. (2001). On the Design of Adaptive Automation for Complex Systems. International Journal for Cognitive Ergonomics.

Keysar, B., Barr, D. J., Balin, J. A., \& Paek, T. S. (1998). Definite Reference and Mutual Knowledge: Process Models of Common Ground in Comprehension. Journal of Memory and Language, vol 39, no 1, pp 1-20.

Kircher, K., Larsson, A., \& Hultgren, J. A. (2014). Tactical driving behavior with different levels of automation. IEEE Transactions on Intelligent Transportation Systems, vol 15, pp 158-167.

Klein, G., Woods, D. D., Bradshaw, J. M., Hoffman, R. R., \& Feltovich, P. J. (2004). Ten Challenges for Making Automation a "Team Player" in Joint Human-Agent Activity. IEEE Intelligent Systems.

Leveson, N. (2004). A new accident model for engineering safer systems. Safety Science, vol 42, no 4, pp 237-270.

Meng, F., \& Spence, C. (2015). Tactile warning signals for in-vehicle systems. Accid Anal Prev, vol 75, pp 333-346.

Merat, N., Jamson, A. H., Lai, F. F. C. H., Daly, M., \& Carsten, O. M. J. (2014). Transition to manual: Driver behaviour when resuming control from a highly automated vehicle. Transportation Research Part F: Traffic Psychology and Behaviour, vol 26, Part A, pp 1-9. 
Michon, J. A. (1985). A critical view of driver behavior models: What do we know, what should we do? In L. Evans \& R. C. Schwing (Eds.), Human behavior and traffic safety. New York: Plenum Press.

Miles, T. (2014, May 19, 2014). Cars could drive themselves sooner than expected after European push.

Min, D., Chung, Y. H., \& Yoon, W. C. (2004). Comparative Analysis of Communication at Main Control Rooms of Nuclear Power Plants. Paper presented at the Proceedings of IFAC/IFIP/IFORS/IEA Symposium.

Molesworth, B. R. C., \& Estival, D. (2015). Miscommunication in general aviation: The influence of external factors on communication errors. Safety Science, vol 73, no 0, pp 73-79.

Molloy, R., \& Parasuraman, R. (1996). Monitoring an automated system for a single failure: Vigilance and task complexity effects. Human Factors, vol 38, no 2, pp 311-322.

National Transportation Safety Board. (1997). In-flight icing encounter and uncontrolled collision with terrain Comair Flight 3272 Embraer EMB-120RT, N265CA.

Norman, D. A. (1983). Design Rules Based on Analyses of Human Error. Communications of the Acm, vol 26, no 4, pp 254-258.

Norman, D. A. (1990). The Problem of Automation, Inappropriate Feedback and Interaction, Not Over-Automation. Philosophical Transactions of the Royal Society of London B: Biological Sciences, vol 327, no 1241, pp 585-593.

Norman, D. A. (2009). The Design of Future Things. New York: Basic Books.

Norman, D. A. (2013). The Design of Everyday things. New York: Basic Books.

Parasuraman, R. (2000). Designing automation for human use: empirical studies and quantitative models. Ergonomics, vol 43, no 7, pp 931-951.

Parasuraman, R., Sheridan, T. B., \& Wickens, C. D. (2000). A model for types and levels of human interaction with automation. IEEE Trans Syst Man Cybern A Syst Hum, vol 30, no 3, pp 286297.

Patterson, E. S., \& Woods, D. D. (2001). Shift changes, updates, and the on-call architecture in space shuttle mission control. Comput Support Coop Work, vol 10, no 3-4, pp 317-346.

Rankin, A., Woltjer, R., Field, J., \& Woods, D. D. (2013). "Staying ahead of the aircraft" and Managing Surprise in Modern Airliners. Paper presented th the 5th Resilience Engineering Symposium: Mangaging trade-offs, Soesterberg, The Netherlands.

Rundquist, S. (1992). Indirectness: A gender study of flouting Grice's maxims. Journal of Pragmatics, vol 18, no 5, pp 431-449.

Rushby, J., Crow, J., \& Palmer, E. (1999). An automated method to detect potential mode confusions. Paper presented at the Digital Avionics Systems Conference.

Russell, H. E. B., Harbott, L. K., Nisky, I., Pan, S., Okamura, A. M., \& Gerdes, J. C. (2016). Motor learning affects car-to-driver handover in automated vehicles. Science Robotics, vol 1, no 1.

SAE J3016. (2016). Taxonomy and Definitions for Terms Related to Driving Automation Systems for On-Road Motor Vehicles, J3016_201609: SAE International.

Sarter, Woods, \& Billings. (1997). Automation Surprises. In G. Salvendy (Ed.), Handbook of Human Factors \& Ergonomics.

Sarter, N. B., \& Woods, D. D. (1995). How in the World Did We Ever Get into That Mode - Mode Error and Awareness in Supervisory Control. Human Factors, vol 37, no 1, pp 5-19.

Seppelt, B. D., \& Lee, J. D. (2007). Making adaptive cruise control (ACC) limits visible. International Journal of Human-Computer Studies, vol 65, no 3, pp 192-205.

Sheridan, T. B. (1995). Human centered automation: Oxymoron or common sense? 1995 leee International Conference on Systems, Man and Cybernetics, Vols 1-5, pp 823-828.

Sheridan, T. B., \& Parasuraman, R. (2005). Human-Automation Interaction. Reviews of Human Factors and Ergonomics, vol 1, no 1, pp 89-129.

Sperber, D., \& Wilson, D. (1986). Relevance: Communication and cognition. Oxford: Blackwell. Stalnaker, R. (2002). Common Ground. Linguistics and Philosophy, vol 25, no 5/6, pp 701-721. 
Stanton, N. A. (2015, March). Responses to Autonomous Vehicles. Ingenia, no 62, pp 69.

Stanton, N. A., Dunoyer, A., \& Leatherland, A. (2011). Detection of new in-path targets by drivers using Stop \& Go Adaptive Cruise Control. Appl Ergon, vol 42, no 4, pp 592-601.

Stanton, N. A., Young, M., \& McCaulder, B. (1997). Drive-by-wire: The case of driver workload and reclaiming control with adaptive cruise control. Safety Science, vol 27, no 2-3, pp 149-159.

Strand, N., Nilsson, J., Karlsson, I. C. M., \& Nilsson, L. (2014). Semi-automated versus highly automated driving in critical situations caused by automation failures. Transportation Research Part F: Traffic Psychology and Behaviour.

Summala, H. (2000). Brake Reaction Times and Driver Behavior Analysis. Transportation Human Factors, vol 2, no 3, pp 217-226.

Surian, L. (1996). Are Children with Autism Deaf to Gricean Maxims? Cognitive Neuropsychiatry, vol 1 , no 1 , pp 55-72.

Swaroop, D., \& Rajagopal, K. R. (2001). A review of Constant Time Headway Policy for Automatic Vehicle Following. Paper presented at the IEEE Intelligent Transportation Systems Conference Proceedings, Oakland (CA), USA.

Vanderhaegen, F., Chalmé, S., Anceaux, F., \& Millot, P. (2006). Principles of cooperation and competition: application to car driver behavior analysis. Cognition, Technology \& Work, vol 8, no 3, pp 183-192.

Weick, K. E., Sutcliffe, K. M., \& Obstfeld, D. (2005). Organizing and the process of sensemaking. Organization Science, vol 16, no 4, pp 409-421.

Wiener, E. L. (1989). Human Factors of Advanced Technology ("Glass Cockpit") Transport Airrcraft. NASA Contractor Report 177528.

Willemsen, D., Stuiver, A., \& Hogema, J. (2015). Automated Driving Functions Giving Control Back to the Driver: A Simulator Study on Driver State Dependent Strategies. Paper presented at the 24th International Technical Conference on the Enhanced Safety of Vehicles (ESV).

Wilson, S., Galliers, J., \& Fone, J. (2007). Cognitive artifacts in support of medical shift handover: An in use, in situ evaluation. International Journal of Human-Computer Interaction, vol 22, no 12, pp 59-80.

Wolterink, W. K., Heijenk, G., \& Karagiannis, G. (2011). Automated Merging in a Cooperative Adaptive Cruise Control (CACC) System. Paper presented at the Fifth ERCIM Workshop on eMobility, Vilanova i la Geltrú, Catalonia, Spain.

Woods, D. D. (1993). Price of Flexibility in Intelligent Interfaces. Knowledge-Based Systems, vol 6, no 4, pp 189-196.

Woods, D. D. (1996). Decomposing Automation: Apparent Simplicity, Real Complexity. In R. Parasuraman \& M. Mouloua (Eds.), Automation and Human Performance: Theory and Applications.

Woods, D. D., \& Patterson, E. S. (2000). How Unexpected Events Produce An Escalation Of Cognitive And Coordinative Demands. In P. A. Hancock \& P. Desmond (Eds.), Stress Workload and Fatigue. Hillsdale: NJ: Lawrence Erlbaum Associates.

Young, M. S., \& Stanton, N. A. (1997). Automobile automation: Investigating the impact on driver mental workload. International Journal of Cognitive Ergonomics, vol 1, no 4, pp 325-336.

Young, M. S., \& Stanton, N. A. (2002). Malleable attentional resources theory: a new explanation for the effects of mental underload on performance. Hum Factors, vol 44, no 3, pp 365-375.

Young, M. S., \& Stanton, N. A. (2007a). Back to the future: brake reaction times for manual and automated vehicles. Ergonomics, vol 50, no 1, pp 46-58.

Young, M. S., \& Stanton, N. A. (2007b). What's skill got to do with it? Vehicle automation and driver mental workload. Ergonomics, vol 50, no 8, pp 1324-1339.

Young, M. S., Stanton, N. A., \& Harris, D. (2007). Driving automation: learning from aviation about design philosophies. International Journal of Vehicle Design, vol 45, no 3, pp 323-338. 